\title{
The UK Near Earth Object Information Centre (NEOIC)
}

\author{
Iwan P. Williams \\ Astronomy Unit, Queen Mary, University of London, London, E1 4NS, UK \\ email: i.p.williams@qmul.ac.uk
}

\begin{abstract}
Following the report of the 'task force', the UK Government decided to accept some of it's recommendations. In particular, it accepted two that recommended the setting up of a British National Centre for Near Earth Objects. The final outcome was the setting up of a Near Earth Object Information Centre to inform the general public of the dangers or otherwise from impact on the Earth of Near Earth Objects. The Centre has now been running for several years and in this publication we examine the current workings of the Centre and discuss some of its successes and failures.
\end{abstract}

Keywords. Impact risk; outreach activities

\section{Historical Introduction}

The story start in 1694 when Edmund Halley suggested that some global catastrophes could have been caused by cometary impacts. In particular, he suggested that one such impact may have been the cause of the event that lead to the biblical flood legend while an other impact could have formed the Caspian Sea. Such views were not however popular in Halley's time, when it was generally believed that the heavens, being God's creation, were perfect. Collisions between heavenly bodies simply could not take place. A hundred years later, Chladni (1794) proposed that meteorites could be of extra-terrestrial origin, but the idea that heavenly bodies could collide was still not generally accepted as is illustrated by the following. In December 1807 a huge fireball was seen by many people over a large section of New England and a meteorite was observed crashing to Earth near Weston, Connecticut. Two employees of what was then called Yale College, Sillman, a professor of Chemistry, and Kingsley, the college librarian, collected many samples of this Weston meteorite, but US President Thomas Jefferson is attributed with the probably apocryphal remark 'it is easier to believe that two Yankee Professors would lie than that stones would fall from the sky'.

However, evidence for collisions was mounting rapidly. For example Benzenberg and Brandes (1800) had observed the same 22 meteor trails from two different sites. They showed from parallax measurements that their average height was about $90 \mathrm{~km}$. This was far too high for them to be a normal atmospheric phenomena and so they must have an extra-terrestrial cause. The spectacular Leonid meteor storms of 1833 convinced most people that small particles could regularly crash into the Earth. However, to believe that larger object, large enough to cause physical damage, could collide was a different matter. In the 1890's Barringer suggested that what is now called meteor crater in Arizona was of impact origin and in the 1930's, the Odessa crater in Texas was shown to be an impact crater.

Through the discoveries of an increasing number of asteroids on Earth approaching orbits, the idea that larger bodies could collide with the Earth slowly became acceptable and in the 1970's, Eleanor Helin together with Eugene and Carolyn Shoemaker started 
a systematic photographic survey of the sky with the primary aim of discovering NearEarth Objects. At about the same time, Arthur C Clarke coined the term Spaceguard to describe the general activity of guarding the Earth against impacts from Near Earth Objects. In 1979, the film 'Meteor' was released, perhaps bringing the subject to the notice of the general public for the first time. The awareness of the public regarding the topic was increased further when Alvarez et al. (1980) suggested that the extinction of the dinosaurs could be explained through a massive asteroidal impact.

The 1980's saw a general increase in the acceptance of the idea that asteroids and comets could, and indeed did, collide with the Earth. This, in turn, led to an increase in the number of survey facilities being established in order to search for potential collision candidates. In 1991, the US Congress House Committee on Science and Technology direct NASA to study the feasibility of having a programme that would increase detection rates of asteroids on Earth-crossing orbits. This lead to the publication in 1992 of the Spaceguard Survey report which recommended a search programme and international collaboration to find objects greater than $1 \mathrm{~km}$ through the provision of six ground based telescopes suitably placed around the world. Half the cost of these telescopes was expected to come from international partners and half from the US.

In 1994, the above report was modified so that NASA was requested to report within one year, with help from the US Department of Defence and the Space Agencies of other countries, on the setting up of a programme to identify and catalogue all comets and asteroids with a diameter greater than $1 \mathrm{~km}$ that are on an orbit that crosses the Earth's orbit. In that year, the fragments from the break-up comet Shoemaker-Levy 9 were discovered and many of the fragment were observed as they collided with Jupiter, leaving visible scars on the planet. This provided a considerable upturn in the interest of the public in the matter of asteroid and comet collisions with the Earth. At the IAU General Assembly in the same year, a recommendation that some (unspecified) International Authority should take responsibility for NEO investigations was passed.

Over the next five years there are many conferences held on the subject and many resolutions passed. However, little action takes placed other than in the US, where new surveys facilities continue to be established and the IAU which continues to keep catalogues of Near Earth Object orbits through its Minor Planet Center.

In 1999, the UK Science Minister, Lord Sainsbury, in a speech to the House of Lords stated that Britain must cooperate internationally in order to tackle the threat presented by Near Earth Objects. One year later he created a Task Force that was required to investigate the topic of Potentially Hazardous Near Earth Objects and to make recommendations to the UK Government on how it should best contribute to an international effort on Near Earth Objects. In particular, the Task Force was required to

(a) confirm the nature of the hazard and assess the potential levels of risk;

(b) identify the current contribution of the UK to international efforts;

(c) advise the Government on what further action to take in the light of their findings with regard to points 1 and 2 above;

(d) advise the Government on how to communicate the issues to the public;

(e) send their report to the Director General of the British National Space Centre (BNSC) by the middle of the year 2000 .

This paper deals with progress made in the UK from that date until now.

\section{The Task Force Report}

The Task Force was chaired by Dr Harry Atkinson with Sir Crispin Tickell and Professor David Williams as members. The report was published in September 2000 and can be 
found at http://www.nearearthobjects.co.uk. It provided an excellent overview of the subject at the time of publication and, in addition, made 14 recommendations to the UK Government. These recommendation are not reproduced in full here but a summary of each is given.

\subsection{Survey and Discovery of Near Earth Objects}

\section{Recommendation 1}

The UK Government should seek partners, preferably in Europe, to build a new advanced 3 meter survey telescope located somewhere in the Southern Hemisphere. This telescope should be dedicated to work on Near Earth objects.

\section{Recommendation 2}

Arrangements should be made so that any observational data obtained for other purposes by wide-field facilities such as the new VISTA telescope would be searched for NEO's on a nightly basis.

\section{Recommendation 3}

The UK Government should draw the attention of ESA to the role that GAIA and other space missions such as BepiColombo and NASA's SIRTIF could play in surveying the sky for NEO's

\subsection{Accurate orbit determination}

\section{Recommendation 4}

The $1 \mathrm{~m}$ Johanes Kapteyn Telescope located on La Palma should be dedicated to follow-up astrometric observations of NEO's

\subsection{Composition and gross properties}

\section{Recommendation 5}

Negotiations should take place with all the partners that the UK share suitable telescopes with to establish an arrangement such that small amounts of time is provided for spectroscopic follow-up of NEO's

\section{Recommendation 6}

The UK Government, together with like-minded countries, should explore the case for mounting a number of coordinated space rendezvous missions based on using microsatellites.

\subsection{Coordination of astronomical observations}

\section{Recommendation 7}

The UK Government together with other Governments, the IAU and other interested parties should seek ways of putting the governance and funding of the IAU Minor Planet Center on a robust international footing.

\subsection{Studies of impact on the environmental and consequential social effects}

\section{Recommendation 8}

The UK Government should help to promote multi-disciplinary studies of the consequences on Earth of impacts from NEO's.

\subsection{Mitigation possibilities}

\section{Recommendation 9}

The UK Government, with other Governments, should set in hand studies to look at ways of deflecting any incoming objects and of mitigating the consequences of impact. 


\subsection{Organization}

\section{Recommendation 10}

The UK Government together with other Governments and the IAU should urgently seek to establish a forum for an open discussion of the scientific aspects of NEOs

\section{Recommendation 11}

The UK Government should discuss with like minded Governments in Europe how Europe could best contribute to the international effort to cope with potential NEO impacts. ESA, ESO, the EU and the European Science foundation should work together on a strategy for this purpose.

\section{Recommendation 12}

The UK Government should appoint a single department to take the lead in the coordination and conduct of Government policy regarding NEOs.

\subsection{British National Centre for Near Earth Objects}

\section{Recommendation 13}

A British Centre for Near Earth Objects should be set up. It's mission would be to promote and coordinate work on the subject in Britain as well as providing an advisory service to the Government, the public and the media. It should also help to facilitate British involvement in international activities.

\section{Recommendation 14}

One of the most important functions of a British Centre for NEOs would be to provide a service for the public that would give balanced information in clear direct and comprehensible language as the need might arise.

\section{The British National Centre for Near Earth Objects}

It is a matter of some debate as to how many of the excellent recommendations listed above have actually been implemented by the UK Government. Some were dealt with in a different way from that envisaged in the report, for example recommendation 7 suggested one way of funding the MPC. However, at this meeting we have been informed of new arrangements for the MPC. Other recommendations were overtaken by events, for example recommendation 4 envisaged a role for the Jacobus Kapteyn telescope that can not be fullfilled because of the changed situation in UK optical astronomy, while for some more, other governments were perhaps more reluctant to take part. However at least two were implemented, recommendations 13 and 14 and we give an account here of the implementation of these two recommendations.

\subsection{The formation and structure of the Near Earth Object Information Centre}

The centre came into operation in April 2002, only 18 months after the publication of the Task Force report, a commendably short interval of time. The main centre is based at the National Space Centre located in Leicester. In passing it is important to clarify the distinction between the British National Space Centre (BNSC) which is based in London and the National Space Centre, based in Leicester. The former is a Quasi-Government agency that provides funding for Space Research and directly advises government on policy. The latter is a quasi-private enterprise that is more akin to the Science Museum and derives much of its financial support through its own activities. The Near-Earth Object Information Centre derives its funding primarily through a grant from BNSC, but is based at the National Space Centre in Leicester, which is more appropriate since much of its function is related to public contact. The main current functions of NEOIC are to provide (i) an up to date web site with all relevant information about NEO's, (ii) 
an exhibition which displays in an user-friendly way the full range of topics normally included under the heading of NEO studies and (iii) public lectures and talks, both at the centre and elsewhere, primarily at schools. The raw data is taken from the MPC, the JPL Impact table and the NEODyS risk page. To assist in these task the NEOIC has a team of experts that act as advisors. At present the team consists of Professor Martin Barstow, Dr John Davies, Professor Alan Fitzsimmons, Dr Mathew Genge, Professor Monica Grady, Professor Carl Murray and Professor Iwan Williams. In addition NEOIC has the responsibility of advising BNSC (and thus indirectly the UK Government) on any matters that deserve attention.

The NEOIC has also expanded to provide three Regional Centres, all also based at institutions with a primary function to provide education and information to the public. These are W5 in Belfast, the National History Museum in London and the Royal Observatory in Edinburgh. Each regional centre has its own NEO exhibition based on the main exhibition based at Leicester.

\subsection{The Activities of NEOIC}

In order to perform effectively its outreach tasks, it is necessary that all the information that NEOIC has is up to date. To facilitate this, the Minor Planet Electronic Circulars (MPEC) are monitored daily with all the new data incorporated into the data base. In addition, JPL's Impact Table and NEODyS Risk Page are both monitored daily for changes. All major sources of NEO news stories are also monitored.

With this up to date information, NEOIC basically performs a number of tasks.

1. NEOIC's own web page is updated to reflect any news gained through any of the above activities. It very occasionally highlights a particularly important piece of news, though experience has shown that this can be a dangerous practice, especially when the published orbit is based on a very short observing arc. The average number of users daily has remained fairly constant at about 300, though a peak of 20000 was achieved during an unfortunate incident where NEOIC was premature in announcing a potential impact.

2. It provides regular reports to BNSC an in addition alerts them if a potential future threat has been identified. This is potentially an important role since occasionally a member of Parliament will ask the Science Minister what the UK Government is doing about the possible asteroid collision in 2XXX and the minister needs reliable and up to date information to reply sensibly to such questions.

3. It responds to media activities both through answering journalist questions by email or telephone or by giving interviews. Here the Expert team play an important role since questions, especially from journalists, are often referred to them.

4. By far the main task, both in terms of time and public impact, is what might be called 'outreach activities '. These can be subdivided into three main categories:

a) Exhibitions: these are mainly unstaffed but interactive, and would more often than not be repeated at the Regional Centres. Typical examples are

(i) A computer simulation to 'find' an NEO, with illustration of how the predicted orbit improves with more observational data.

(ii) An interactive map showing that impacts have already happened. Impact sites are shown on a map, which when the mouse is clicked on a dot, a picture of the crater is shown (and possible also the likely size of impactor)

(iii) A view of the Solar System depicting the real motion of known Apollo, Amor or Aten asteroids and certain named comets.

Other 'hands on' activities are also often included, including the handling of real meteorites of different classes, images of comet Shoemaker-Levy 9 and so forth. 
b) External Visits: these involve visiting Schools and Clubs to give an organized presentation via a lecture or talk and demonstrations of the topic. There is nothing particularly novel about this activity, but it is perhaps the back-bone of outreach activities. The main advantage of organizing such an activity through NEOIC is that presentational material can be prepared to a high standard.

c) Workshops: these can take place either at NEOIC or at an external venue. The difference between these and the external visits is to stress the hands-on aspect of the activity. Meteorite fragment are handled by the audience so that they can really see and feel the difference between a stony and an iron one, they help to make a comet nucleus model, or play with 'Newton's Cradle 'to appreciate the law of momentum conservation.

\section{Conclusions}

It is interesting after four years of operation to ask two questions, has it achieved its laid down objectives, and is it worthwhile?

The objectives outlined in recommendations 13 and 14 of the task force report were

(i) To promote and coordinate work on the subject in the UK;

(ii) To provide an advisory service to the UK Government;

(iii) To facilitate British involvement in international activities;

(iv) To provide a public service that gives balanced information;

(v) To provide an advisory service to the public.

In terms of giving the public information, NEOIC has exceeded the demands in terms of exhibitions and outreach activities, it advises the government and gives balanced information to the public. Through these it has also helped to promote and coordinate work in the field, primarily through the expert team. It has done very little to promote and facilitate British involvement in international activities primarily because of a lack of funds.

So, is it worthwhile? The answer has to be yes, the public are now much better informed at a relatively low cast. It also has the side benefit of getting young children interested in astronomy generally and indeed in finding out that science can be fun. It also provides a valuable service in ensuring that UK Government Ministers, particularly the Science Minister has accurate information. It has also, after a few errors, proved to be a reliable source of information for the Press-which is to the good of the subject in the long run.

Of course, it would be nice if it had more money so that it could fund both UK and international cooperation, but moving forward is always better than standing still.

\section{Acknowledgements}

The author would like to thank Kevin Yates the NEOIC project manager for providing lots of information without which this article could not have been written.

\section{References}

Alvarez, L.W. Alvarez, W. Asaro, F. \& Michel, H.V., Science 208, 1095

Benzenberg, J.F. \& Brandes H.W. 1800, Annalen der Physik 6, 224

Chladni, E.F.F. 1794, Hartknock (pub) Riga, 1794 